\title{
Influence of molecular scattering models on aerosol optical properties measured by high spectral resolution lidar
}

\author{
Bing-Yi Liu, ${ }^{1,2, \star}$ Michael Esselborn, ${ }^{2}$ Martin Wirth, ${ }^{2}$ Andreas Fix, ${ }^{2}$ \\ De-Cang $\mathrm{Bi}^{1}{ }^{1}$ and Gerhard Ehret ${ }^{2}$ \\ ${ }^{1}$ Key Laboratory of Ocean Remote Sensing, Ministry of Education of China, \\ Ocean University of China, 5 Yushan Road, Qingdao 266003, China \\ ${ }^{2}$ Deutsches Zentrum für Luft- und Raumfahrt, Institut für Physik der Atmosphäre, \\ Oberpfaffenhofen, 82234 Wessling, Germany \\ ${ }^{*}$ Corresponding author: liuby@orsi.ouc.edu.cn
}

Received 17 February 2009; revised 1 September 2009; accepted 2 September 2009; posted 2 September 2009 (Doc. ID 107689); published 11 September 2009

\begin{abstract}
The influence of molecular scattering models on aerosol optical properties measured by high spectral resolution lidar (HSRL) is experimentally investigated and theoretically evaluated. The measurements analyzed in this study were made during three field campaigns by the German Aerospace Center airborne HSRL. The influence of the respective theoretical model on spaceborne HSRL retrievals is also estimated. Generally, the influence on aerosol extinction coefficient can be neglected for both airborne and spaceborne HSRLs. However, the influence on aerosol backscatter coefficient depends on aerosol concentration and is larger than 3\% (6\%) at ground level for airborne (spaceborne) HSRLs, which is considerable for the spaceborne HSRL, especially when the aerosol concentration is low. A comparison of the HSRL measurements and coordinated ground-based sunphotometer measurements shows that the influence of the model is observable and comparable to the measurement error of the lidar system. () 2009 Optical Society of America
\end{abstract}

OCIS codes: $\quad 010.1280,010.3640,280.1100,290.5870$.

\section{Introduction}

Atmospheric aerosol is an important climate factor and has inherent influence on the Earth's radiative fluxes and climate change [1]. The quantitative measurements of aerosol optical properties are important for the estimation of the aerosols' radiative impact. Spaceborne backscatter lidars have been developed to measure the global distribution of aerosols and clouds. The Geoscience Laser Altimeter System (GLAS) [2] aboard the Ice, Cloud and land Elevation Satellite (ICESat) [3] and the Cloud-Aerosol Lidar with Orthogonal Polarization (CALIOP) [4] of the Cloud-Aerosol Lidar and Infrared Pathfinder Satel-

0003-6935/09/275143-12\$15.00/0

(C) 2009 Optical Society of America lite Observation (CALIPSO) mission [5] are two current systems with the ability to derive aerosol extinction and backscatter coefficients by assuming an extinction-to-backscatter ratio (lidar ratio) [6,7]. However, in this method, the quantitative measurements of aerosol optical properties are limited by the highly variable value of the lidar ratio. High spectral resolution lidar (HSRL) utilizes a narrowband optical filter to separate the aerosol contribution from molecular scattering, so that the extinction coefficient can be directly measured without the assumption of the lidar ratio [8-13]. Airborne HSRLs at $532 \mathrm{~nm}$ using iodine vapor filters to reject aerosol scattering have been successfully developed and demonstrated by the NASA Langley Research Center [14,15] and the German Aerospace Center (DLR) [ $[16-19]$, respectively. In the near future, the Doppler 
wind lidar Atmospheric Laser Doppler Instrument (ALADIN) [20,21] of the European Space Agency's (ESA) Atmospheric Dynamics Mission (ADM) [22,23], which uses a Fabry-Perot interferometer and a Fizeau interferometer at $355 \mathrm{~nm}$ for Rayleigh and Mie detection, respectively, will be the first HSRL in space [24,25]. As part of ESA's Earth Clouds, Aerosols, and Radiation Explorer (EarthCARE) mission [26], the HSRL Atmospheric Lidar (ATLID) at $355 \mathrm{~nm}$ is planned to be employed for direct aerosol extinction measurements with a Fabry-Perot interferometer [27]. These two spaceborne HSRLs will offer the opportunity for quantitative measurements of aerosol and cloud properties on a global scale.

The information of molecular scattering can be obtained by using iodine vapor filters [11-13] or FabryPerot interferometers [24,25,27]. With an iodine vapor filter, the narrowband aerosol Mie scattering can be suppressed by a factor of $10^{-6}-10^{-5}$ [17], while the wings of the molecular scattering can pass through the iodine vapor filter. In this way, the molecular scattering and the aerosol scattering can be determined separately from a portion of the molecular scattering and the total scattering signals measured independently. In order to retrieve the aerosol optical properties, the amount of molecular scattering blocked by the filter has to be calculated using the measured filter transmission function and the calculated molecular backscatter spectrum. The molecular Rayleigh scattering [28,29] consists of a central peak, termed Cabannes scattering [28-30], and sidebands, termed (pure) rotational Raman scattering. Since the rotational Raman scattering can usually be rejected by a narrowband optical filter in the HSRL, only the Cabannes scattering is taken into account. However, the backscatter spectrum of Cabannes scattering can theoretically be described by different approaches; one approach assumes that the velocity distribution of the air molecules follows that of an ideal gas, thereby leading to a Doppler spectral broadening of the backscatter signal. The other approach accounts for density fluctuations induced by acoustic waves traversing the scattering medium, thereby leading to Brillouin scattering (see Section 2 for details). Since, with different theoretical models, different values of the filter attenuation factor can be obtained, the values of aerosol optical properties also vary with the theoretical models.

The intent of this paper is to investigate the dependence of the aerosol optical properties on the theoretical model of molecular scattering. It is well known that kinetic models are well researched in the case of pure gases but not yet for the atmospheric gas composition. The model has been applied on lidar applications by some authors [31-34]. However, the Gaussian model is a commonly used model in some conditions when the accuracy is not very important, but the quantitative analysis of the model's influences on HSRL aerosol measurements has not been demonstrated for both airborne and spaceborne sys- tems. The main purpose of this paper is to give the quantitative analysis of the influence and to show when the Tenti model must be used and when the Gaussian model can also be used. With the data measured by the DLR airborne HSRL, the aerosol optical properties are retrieved based on the six moment (S6) model, the seven moment (S7) model, and the Gaussian model and, thereby, the deviations induced by the scattering models are analyzed. In addition, according to the HSRL retrieval method, the models' influences are theoretically calculated using different reference atmospheres without HSRL measurements and then compared with the result obtained from airborne measurements to make sure the theoretical calculation can be used for spaceborne HSRLs. The major factors influencing aerosol optical properties in both airborne and spaceborne HSRLs are described. In addition, to provide an example of the influence of backscatter models on the aerosol optical properties, a comparison of the aerosol optical thickness measured with an airborne HSRL and a sunphotometer is presented.

\section{Theory}

The HSRL method for the retrieval of aerosol optical properties $[13,17]$ is described here for the sake of consistency. For the iodine-vapor-filter-based HSRL, the attenuation factor $f_{m}$ of the Cabannes spectrum through the filter can be written as

$$
f_{m}(T, p)=\int F(\nu) \int \Re\left(\nu^{\prime}, T, p\right) l\left(\nu-\nu^{\prime}\right) \mathrm{d} \nu^{\prime} \mathrm{d} \nu,
$$

where $l(\nu)$ is the transmitting laser profile with a bandwidth of less than $90 \mathrm{MHz} . F(\nu)$ is the iodine vapor filter transmission function normalized to the maximum transmission rate and can be obtained from measurement by continuously tuning the frequency of the laser transmitter over the frequency range of the iodine absorption line and measuring the transmission of laser pulses through the iodine filter. $\Re(\nu, T, p)$ is the normalized temperature- and pressure-dependent Cabannes scattering spectrum. The Cabannes scattering, associated with elastic scattering, has features that reflect the translational motion of the air molecules. In the low-pressure or high-temperature regime, the velocity distribution of the air molecules is thermally dominated and is recognized as a Gaussian distribution. The frequency of the scattered light is shifted by the Doppler effect associated with the thermal motion and, therefore, the spectral profile of the backscattered light has the same shape as the velocity distribution and can be described by a Gaussian model. However, at high pressure or low temperature, the mean free path of molecules becomes shorter. If this mean free path is comparable with the scattering wavelength, density fluctuations caused by the propagation of acoustic waves will be observable. Since the velocity distribution of the air molecules is changed by the traveling acoustic waves, the spectral distribution of scattered 
light changes and the acoustic sidebands (termed Brillouin scattering) appear [35]. The Tenti S6 model [31] takes into account the acoustic sidebands and provides a kinetic model of Cabannes scattering from molecular gases in all regimes. It assumes the gas is composed of a single monatomic or diatomic species. For the calculation in this study, the atmosphere is assumed to be composed of a single diatomic species with a molecular mass of $28.8 \mathrm{~kg} / \mathrm{kmol}$ for air molecules. The ratio of shear viscosity to bulk viscosity (1.407) and the ratio of shear viscosity to thermal conductivity (0.198) of nitrogen are used due to the lack of data for air molecules [34]. A copy of Tenti's FORTRAN program from Forkey [36] is utilized. The main difference between the S7 model and the S6 model is that the $\mathrm{S} 7$ model has one more physical quantity in the derivation [32]. A FORTRAN program of the S7 model was provided by Shneider [37]. Figure 1 shows two examples of molecular backscatter spectra at both low altitude and around $10 \mathrm{~km}$. Additionally, the iodine absorption spectrum is shown. The molecular backscatter spectra before
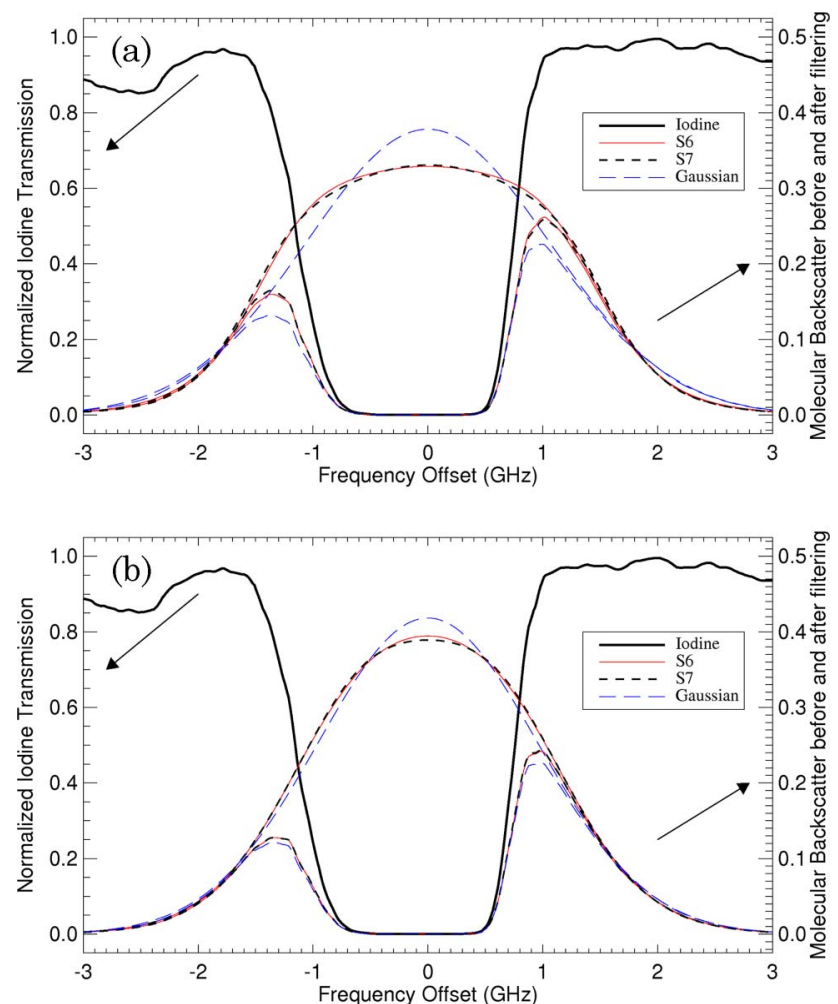

Fig. 1. (Color online) Measured iodine absorption line (thick solid curve) at $563.244 \mathrm{THz}(532.26 \mathrm{~nm})$ together with the normalized molecular backscatter spectrum per gigahertz before (upper curves) and after (lower curves) filtering. The thin solid curves, the thick dashed curves, and the thin dashed curves are calculated with the S6 model, the S7 model, and the Gaussian model, respectively. (a) For standard air $\left(1000 \mathrm{hPa}, 0^{\circ} \mathrm{C}\right)$, the attenuation factors of molecular backscatter are $0.395,0.397$, and 0.369 for the S6 model, the S7 model, and the Gaussian model, respectively. (b) At an altitude of $10 \mathrm{~km}\left(250 \mathrm{hPa},-50^{\circ} \mathrm{C}\right)$, the attenuation factors of molecular backscatter are $0.332,0.333$, and 0.325 for the S6 model, the S7 model, and the Gaussian model, respectively. and after filtering are calculated with the S6 model, the S7 model, and the Gaussian model. At a pressure of $1000 \mathrm{hPa}$ and a temperature of $0^{\circ} \mathrm{C}$ [Fig. 1(a)], due to the contribution of the acoustic sidebands, the spectra of the S6 and S7 models have broader profiles $(\mathrm{FWHM}=2.98$ and $3.01 \mathrm{GHz})$ but lower maximum intensities compared with the spectrum of the Gaussian model (FWHM $=2.48 \mathrm{GHz})$. Therefore, the spectra of the S6 and S7 models have higher transmission factors $\left(f_{m}=0.395\right.$ and 0.397$)$ through the iodine absorption line compared to the Gaussian model $\left(f_{m}=0.369\right)$. This difference leads to deviations or errors in the retrieved aerosol optical properties. With the increase of altitude, the decreases of temperature and pressure have opposite contributions to the intensity of the acoustic sidebands, but actually the change of pressure contributes more. Therefore, at high altitude with low pressure, the translational motion of the air is thermally dominated, which makes the spectral lineshapes of the models more similar. Figure 1(b) shows the example at $10 \mathrm{~km}$ with a pressure of $2 \overline{50 \mathrm{hPa}}$ and temperature of $-50{ }^{\circ} \mathrm{C}$. The linewidth of the backscatter spectrum and the attenuation factor $f_{m}$ are $2.43 \mathrm{GHz}$ and 0.332 for the $\mathrm{S} 6$ model, $2.45 \mathrm{GHz}$ and 0.333 for the $\mathrm{S} 7$ model, and $2.24 \mathrm{GHz}$ and 0.325 for the Gaussian model. Figure 2 shows the absolute errors of the attenuation factors of molecular backscatter from applying the Gaussian model. The temperature and pressure profiles used for analysis are from the Air Force Geophysics Laboratory (AFGL) atmospheric constituent profiles [38], which consist of the six most-used reference atmospheres: tropical, midlatitude summer, midlatitude winter, subarctic summer, subarctic winter, and U.S. standard atmospheres. The error bars show the maximum error range due to different atmospheres. The model's influence decreases with altitude and, therefore, the differences of the retrieved aerosol optical properties decrease with altitude (see Section 4 for details).

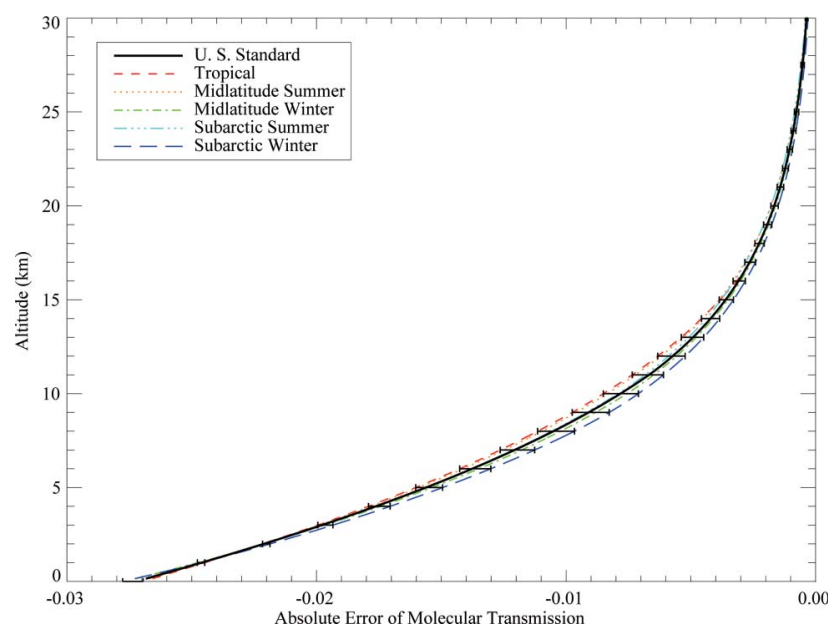

Fig. 2. (Color online) Absolute error of the attenuation factors of molecular backscatter from applying the Gaussian model calculated based on the six reference atmospheres. The error bars show the maximum error range due to different atmospheres. 
In the HSRL systems using iodine filters $[13,17]$, the received energy in the integration time from distance $r$ in the total scattering channel $E_{t}$ and the molecular channel $E_{m}$ can be written as

$$
\begin{gathered}
E_{t}(r)=\eta_{t} E_{0} \frac{A}{r^{2}} \Delta r\left[\beta_{m}(r)+\beta_{a}(r)\right] \tau^{2}(r), \\
E_{m}(r)=\eta_{m} E_{0} \frac{A}{r^{2}} \Delta r\left[\beta_{m}(r) f_{m}(r)+\beta_{a}(r) f_{a}\right] \tau^{2}(r), \quad(2 \mathrm{~b}) \\
\tau^{2}(r)=\tau_{m}^{2}(r) \tau_{a}^{2}(r)=\exp \left\{-2 \int_{0}^{r}\left[\alpha_{m}\left(r^{\prime}\right)+\alpha_{a}\left(r^{\prime}\right)\right] \mathrm{d} r^{\prime}\right\},
\end{gathered}
$$

where $\eta$ is the channel efficiency that includes the efficiencies of optical components such as telescope, mirrors, and, for the molecular channel, the maximum transmission of the filter. $E_{0}$ is the energy of transmitting laser pulses summed over the integration time, $A$ is the area of the receiving telescope, $\Delta r$ is the range resolution, and $\tau^{2}(r)$ is the two-way atmospheric transmission, composed of a molecular $\tau_{m}^{2}(r)$ and an aerosol $\tau_{a}^{2}(r)$ contribution, over range $r$ from the lidar transmitter to the position of scattering. $\beta_{m}$ and $\beta_{a}\left(\alpha_{m}\right.$ and $\left.\alpha_{a}\right)$ are molecular and aerosol volume backscatter (extinction) coefficients, respectively. $f_{a}$ is the attenuation factor of the aerosol signal through the iodine filter. Under normal conditions, because of the low transmission of aerosol scattering through the iodine filter, the product of $\beta_{a}$ and $f_{a}$ approaches zero in the case of the molecular channel; then it can be neglected in Eq. (2b). For simplification in the following analysis, the temperature- and pressure-dependent attenuation factor $f_{m}(T, p)$ in Eq. (1) is converted to range-dependent parameter $f_{m}(r)$ by substituting the temperature and pressure profiles, $T(r)$ and $p(r)$, into $f_{m}(T, p)$. The temperature and pressure profiles can be obtained from either radiosonde measurements or reference atmospheres. It should be noted that, although the range-dependent attenuation factor $f_{m}(r)$ appears to be variable only with range $r$, the fundamental cause for the variation is the change of the Cabannes backscatter spectrum $\Re(\nu, T, p)$ due to temperature and pressure.

From the measurement in the molecular channel as shown in Eq. (2b), the aerosol extinction coefficient $\alpha_{a}(r)$ can be derived as

$$
\alpha_{a}(r)=-\frac{1}{2} \frac{d}{d r}\left[\ln \frac{E_{m}(r) r^{2}}{\beta_{m}(r) f_{m}(r)}\right]-\alpha_{m}(r)
$$

where $\beta_{m}$ and $\alpha_{m}$ can be calculated using the given atmospheric temperature and pressure.

The backscatter ratio $R_{b}=\left(\beta_{m}+\beta_{a}\right) / \beta_{m}$ and the aerosol backscatter coefficient $\beta_{a}$ can be determined from the ratio of the total scattering channel and the molecular channel as

$$
\begin{gathered}
R_{b}(r)=\frac{\eta_{m}}{\eta_{t}} \frac{E_{t}(r)}{E_{m}(r)} f_{m}(r), \\
\beta_{a}(r)=\left[\frac{\eta_{m}}{\eta_{t}} \frac{E_{t}(r)}{E_{m}(r)} f_{m}(r)-1\right] \beta_{m}(r) .
\end{gathered}
$$

To calculate the profiles of the aerosol backscatter coefficient and the backscatter ratio from the measured signals with Eqs. (4), the value of $\eta_{m} / \eta_{t}$ should be determined by the Rayleigh normalization [17]. In this process, at a certain height (the normalization height $r_{0}$ ) where the aerosol backscatter is negligible, the value of $R_{b}\left(r_{0}\right)$ can be obtained either by in situ measurement as discussed in Esselborn et al. [17] or by setting $R_{b}\left(r_{0}\right)$ close to 1 . Then, at the normalization height $r_{0}$, the value of $\eta_{m} / \eta_{t}$ can be derived from Eq. (4a) with the value of $R_{b}\left(r_{0}\right)$, the measured signal $E_{t}\left(r_{0}\right)$ and $E_{m}\left(r_{0}\right)$, and the calculated value $f_{m}\left(r_{0}\right)$. Consequently, the profiles of $R_{b}(r)$ and $\beta_{a}(r)$ can be obtained. The Rayleigh normalization is necessary for the HSRLs described in Hair et al. [13] and Esselborn et al. [17], because the absolute channel efficiency cannot be obtained from internal calibration. For the HSRL described in Hair et al. [15], the absolute channel efficiency can be determined by the internal calibration process. The future spaceborne HSRL EarthCARE will perform the Rayleigh calibration with the return from the aerosol-free area in the higher atmosphere [39].

The values of both extinction and backscatter coefficients not only depend on the measured energy $E_{t}(r)$ and $E_{m}(r)$, but also on the theoretically calculated value $f_{m}(r)$, which depends on the theoretical backscatter model, such as the $\mathrm{S} 6$ model, the $\mathrm{S} 7$ model, and the Gaussian model.

\section{Methods}

The data used for this analysis were measured with the airborne HSRL at $532 \mathrm{~nm}$ implemented in the Water Vapour Lidar Experiment in Space (WALES) [40] system developed by DLR. The detailed description of the lidar system can be found in Wirth et al. [19]. The laser transmitter is a high-power, singlelongitudinal-mode, and frequency-stabilized Nd:YAG laser in a master oscillator/power amplifier configuration followed by a temperature-controlled KTP crystal for frequency doubling. The received backscatter light is split into its polarized components. The parallel-polarized component is split again into a total scattering channel and a molecular channel to measure the intensity of the combined and molecular backscatter separately. An iodine vapor cell in dual-pass configuration is used in the molecular channel to eliminate the aerosol backscatter [17]. The temperature-controlled iodine vapor cell was operated at a vapor pressure of approximately $50 \mathrm{~Pa}$. The 1109 iodine absorption line [41] was used for the measurements.

The aerosol extinction and backscatter coefficients are calculated from the measurements by the total scattering channel and the molecular channel using 
Eqs. (3) and (4). To investigate the impact of the theoretical scattering model on the aerosol optical properties, the value of $f_{m}$ is calculated based on the $\mathrm{S} 6$ model, the S7 model, and the Gaussian model. Since the Tenti S6 theoretical model is generally considered to be the most accurate for diatomic gases [42], aerosol optical properties retrieved using the $\mathrm{S} 6$ model are taken as a reference in this study. Therefore, the errors of aerosol optical properties due to the Gaussian model and the S7 model can be estimated. The absolute error $\Delta x$ and relative error $\delta x$ are calculated as follows:

$$
\begin{gathered}
\Delta x_{i, j}=x_{i}-x_{j}, \\
\delta x_{i, j}=\frac{x_{i}-x_{j}}{x_{j}} \times 100 \%,
\end{gathered}
$$

where $i, j=\mathrm{S} 6, \mathrm{~S} 7$, or $\mathrm{G} . x_{\mathrm{S} 6}, x_{\mathrm{S} 7}$ and $x_{\mathrm{G}}$ are the aerosol optical properties retrieved with the $\mathrm{S} 6$, the $\mathrm{S} 7$, and the Gaussian models, respectively.

In addition, the errors can also be theoretically derived. Actually, there are many potential error sources related to aerosol retrieval, such as temperature uncertainty, pressure uncertainty, and signalto-noise ratio. In this study, only the errors from scattering models are discussed. Using the profiles of atmospheric temperature and pressure from a reference atmosphere, the errors that are independent of the measured values $\left(E_{t}\right.$ and $\left.E_{m}\right)$ can be derived without HSRL measurements. The absolute error of the aerosol extinction coefficient $\Delta \alpha_{a}$, the relative error of the backscatter ratio $\delta R_{b}$, and the relative error of the aerosol backscatter coefficient $\delta \beta_{a}$ are derived in Appendix $\underline{\mathrm{A}}$ and are expressed as

$$
\begin{gathered}
\Delta \alpha_{a, i, j}(r)=\frac{1}{2}\left[\frac{d f_{m, i}(r) / d r}{f_{m, i}(r)}-\frac{d f_{m, j}(r) / d r}{f_{m, j}(r)}\right], \\
\delta R_{b, i, j}(r)=\delta f_{m, i, j}^{\prime}(r), \\
\delta \beta_{a, i, j}(r)=\left[\frac{\beta_{m}(r)}{\beta_{a, j}(r)}+1\right] \delta f_{m, i, j}^{\prime}(r),
\end{gathered}
$$

where $i, j=\mathrm{S} 6, \mathrm{~S} 7$, and $\mathrm{G}$ stand for the $\mathrm{S} 6$ model, the S7 model, and the Gaussian model, respectively. $f_{m}^{\prime}$ is the normalized $f_{m}$, which is defined as $f_{m}^{\prime}(r)=$ $f_{m}(r) / f_{m}\left(r_{0}\right)$, where $r_{0}$ is the normalization height. $\delta f_{m}^{\prime}$ defined in Appendix A is the relative error of the $f_{m}^{\prime}$. The parameter $\delta f_{m}^{\prime}$ indicates the difference between the theoretical scattering models and influences the values of $\delta R_{b}$ and $\delta \beta_{a}$, as shown in Eqs. (7) and (8). The value of $\delta f_{m}^{\prime}$ is determined by the atmospheric temperature and pressure together with normalization height $r_{0}$. It can be seen from Eq. (6) that the absolute error of aerosol extinction coefficient $\Delta \alpha_{a}$ depends only on $f_{m}$. According to Eq. (1), with the given laser function, filter function, and the theoretical scattering model, the value of $f_{m}$ depends only on the atmospheric temperature and pressure. In the case of the relative error of the backscatter ratio $\delta R_{b}$ in Eq. (7), it is determined not only by $f_{m}$, but also by the normalization height $r_{0}$, which has an impact on $\delta f_{m}^{\prime}$. In Eq. (8), the relative error of aerosol backscatter coefficient $\bar{\delta} \beta_{a}$ depends on aerosol concentration, atmospheric status (temperature and pressure), and the normalization height, so with given values of these factors, the value of $\delta \beta_{a}$ can also be estimated without HSRL measurements.

\section{Influence of Models on Aerosol Extinction and Backscatter Coefficients}

For the experimental comparison of the models' influence on the aerosol extinction and backscatter coefficients, the airborne HSRL measurements during the Saharan Mineral Dust Experiment (SAMUM) 2008 are used. During the SAMUM 2008, the DLR Falcon research aircraft equipped with the nadir-viewing HSRL was stationed in Praia, the capital of Cape Verde, and performed airborne measurements from 19 January to 6 February. Among a total of nine flight missions, seven flight legs over Praia performed in four days (Table 1) are selected for the comparison of the aerosol properties retrieved from both the Gaussian and the $\mathbf{S 6}$ models. The profiles of atmospheric temperature and pressure are taken from the radiosondes launched from the SAMUM ground station at the Praia airport. Altogether, four radiosonde measurements are used for the seven overflights. The spatial and temporal differences of lidar and radiosonde are kept within

\begin{tabular}{|c|c|c|c|c|c|c|}
\hline Date & Time (UTC) & Averaging Time (s) & $\Delta t$ at $0 \mathrm{~km}(\min )^{a}$ & $\Delta d$ at $0 \mathrm{~km}(\mathrm{~km})^{b}$ & $\Delta t$ at $7 \mathrm{~km}(\min )^{a}$ & $\Delta d$ at $7 \mathrm{~km}(\mathrm{~km})^{b}$ \\
\hline 25 Jan. 2008 & $15: 56$ & 25 & 3 & 3.8 & 36 & 13.0 \\
\hline 25 Jan. 2008 & $16: 12$ & 60 & 19 & 9.1 & 20 & 13.5 \\
\hline 28 Jan. 2008 & $17: 28$ & 150 & 18 & 15.2 & 24 & 18.1 \\
\hline 29 Jan. 2008 & $19: 36$ & 150 & 78 & 3.0 & 121 & 6.1 \\
\hline 29 Jan. 2008 & $20: 01$ & 150 & 53 & 3.3 & 96 & 5.9 \\
\hline 6 Feb. 2008 & $14: 45$ & 150 & 2 & 7.2 & 39 & 10.0 \\
\hline 6 Feb. 2008 & $16: 28$ & 80 & 105 & 32.9 & 56 & 28.9 \\
\hline
\end{tabular}
$33 \mathrm{~km}$ and $105 \mathrm{~min}$. Considering the ascent time and the horizontal movement of the radiosonde, the maximum spatial and temporal differences at $7 \mathrm{~km}$

Table 1. Flight Legs Used for the Analysis of the Model Influences on the Aerosol Extinction and Backscatter Coefficients

${ }^{a}$ The time interval between HSRL measurement and the launch of radiosonde.

${ }^{b}$ The horizontal distance between HSRL measurement and radiosonde launch positions. 
altitude are approximately $29 \mathrm{~km}$ and $121 \mathrm{~min}$, respectively. The profiles of the aerosol optical properties are averaged over 25-150 s during the overflights to keep spatial atmospheric variations small.

An example of the aerosol extinction coefficient measured with airborne HSRL on 25 January 2008 is shown in Fig. 3. The temperature and pressure profiles are obtained from the nearby radiosonde measurements. The profiles are calculated with the S6 model, the S7 model, and the Gaussian model, respectively, to show the influence of the models. As expected, the S6 and S7 models yield identical profiles of the aerosol extinction coefficient (thin solid curve and thick dashed curve), while the Gaussian model leads to a profile with smaller values (thin dashed curve) compared to those of the S6 and S7 models.

To compare the results from the Gaussian model and the S6 model in detail, profiles of the absolute errors of the aerosol extinction coefficient from applying the Gaussian model are shown in Fig. 4. The solid curve is calculated from Eq. (6) using the averaged temperature and pressure profiles of the radiosondes over seven HSRL flights to show the trend of the altitude-dependent errors. The other profiles show the errors from HSRL measurements by applying the corresponding individual radiosonde profiles of temperature and pressure. It can be seen from Fig. 4 that the profiles from HSRL measurements (different symbols) and theoretical calculations (solid curve) have the same trend. The fluctuations in both the experimental and theoretical results are due to the structures in the temperature and pressure profiles measured by each radiosonde. Within the altitude of $0-7 \mathrm{~km}$, the absolute error of aerosol extinction coefficient ranges from approximately 0.003 to $0.002 \mathrm{~km}^{-1}$, which is less than the molecular extinction coefficient in the same altitude range $\left(\sim 0.013-0.007 \mathrm{~km}^{-1}\right)$.

As shown in Eq. (6), the absolute error of aerosol extinction coefficient $\Delta \alpha_{a}(r)$ depends only on the value of $f_{m}(r)$, which is independent of the aerosol

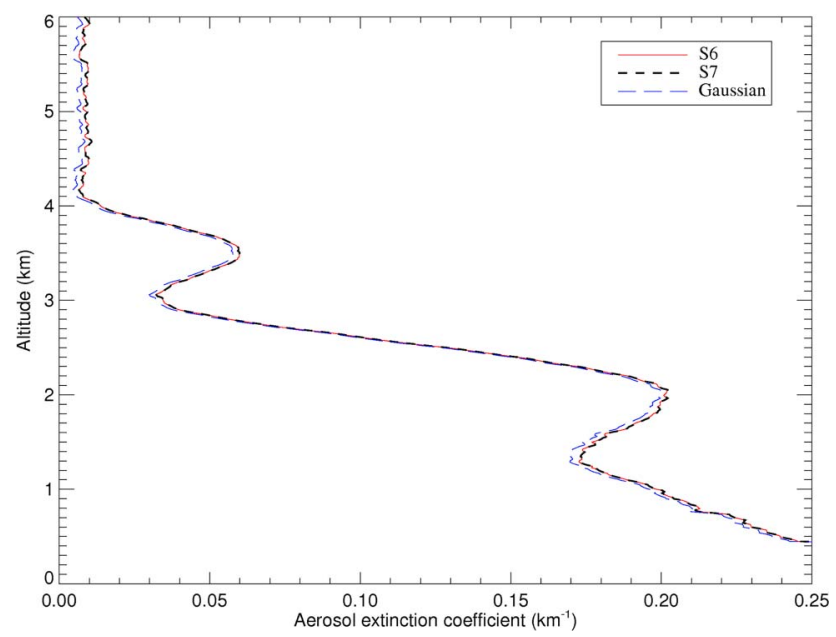

Fig. 3. (Color online) HSRL-measured profiles of the aerosol extinction coefficient (15:56, 25 January 2008, Praia) retrieved using the S6 model, the S7 model, and the Gaussian model.

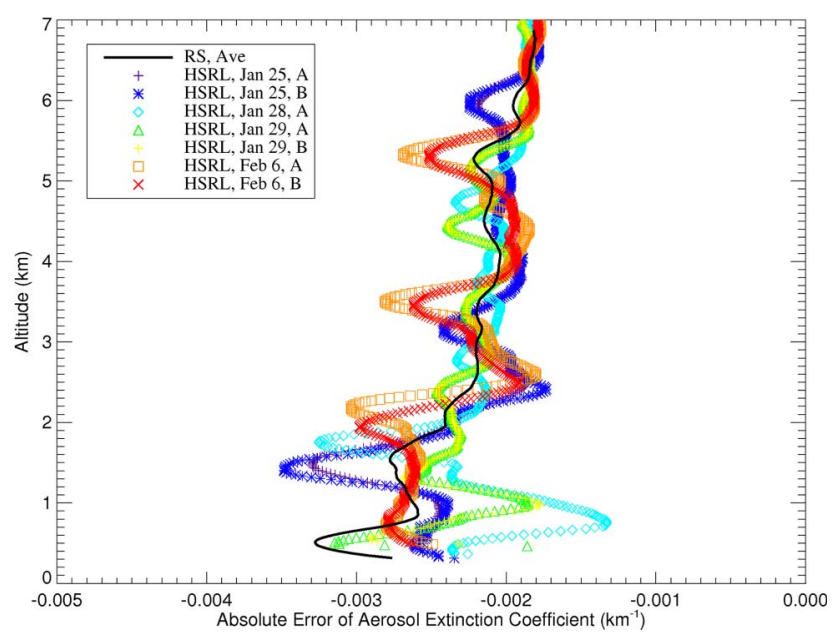

Fig. 4. (Color online) Absolute errors of the aerosol extinction coefficient from applying the Gaussian model calculated using the averaged radiosonde profile (solid curve) and retrieved from the HSRL measurements (different symbols).

concentration and normalization height. According to Eq. (1), with a fixed spectrum of iodine absorption line, $f_{m}(r)$ can be calculated from atmospheric temperature and pressure profiles. Therefore, the absolute error of the aerosol extinction coefficient can be evaluated in the high altitude by Eq. (6) without HSRL measurements. The atmospheric temperature and pressure profiles are from the six reference atmospheres. To calculate the numerical derivative of the attenuation factor $f_{m}(r)$ in Eq. (6), a SavitzkyGolay filter [43] of the first order is used. The theoretical results derived from six different models from ground to $30 \mathrm{~km}$ are shown in Fig. 5, with different curves and the error bars showing the maximum error range due to different models. The value of $30 \mathrm{~km}$ is selected according to the calibration height of $30-34 \mathrm{~km}$ in the case of CALIOP [4] and the higher calibration height of $30 \mathrm{~km}$ (the lower calibration height is between 8 and $15 \mathrm{~km}$ ) in the case of GLAS [44]. Figure 5(a) shows the comparison of the aerosol extinction coefficient retrieved from the Gaussian model and the S6 model. The negative values of the errors mean the results retrieved from the Gaussian model are less than those from the $\mathrm{S} 6$ model. With a maximum value of near $0.003 \mathrm{~km}^{-1}$ in the lowaltitude, the errors decrease with altitude and are less than $0.001 \mathrm{~km}^{-1}$ above $15 \mathrm{~km}$. Below $12 \mathrm{~km}$, the lower (right) and higher (left) sides of the error bar result from the tropical and subarctic winter atmospheres, respectively. However, the situation is the opposite above $12 \mathrm{~km}$. Figure 5(b) shows the theoretical comparison of the aerosol extinction coefficient retrieved from the S7 and S6 models. The positive values of the errors mean the results retrieved from the S7 model are larger than those from the S6 model. Compared with the Gaussian model, the S7 model results in smaller errors, which are approximately $10 \%$ of those from Gaussian model as shown in Fig. 5(a). Since the errors are independent of the 

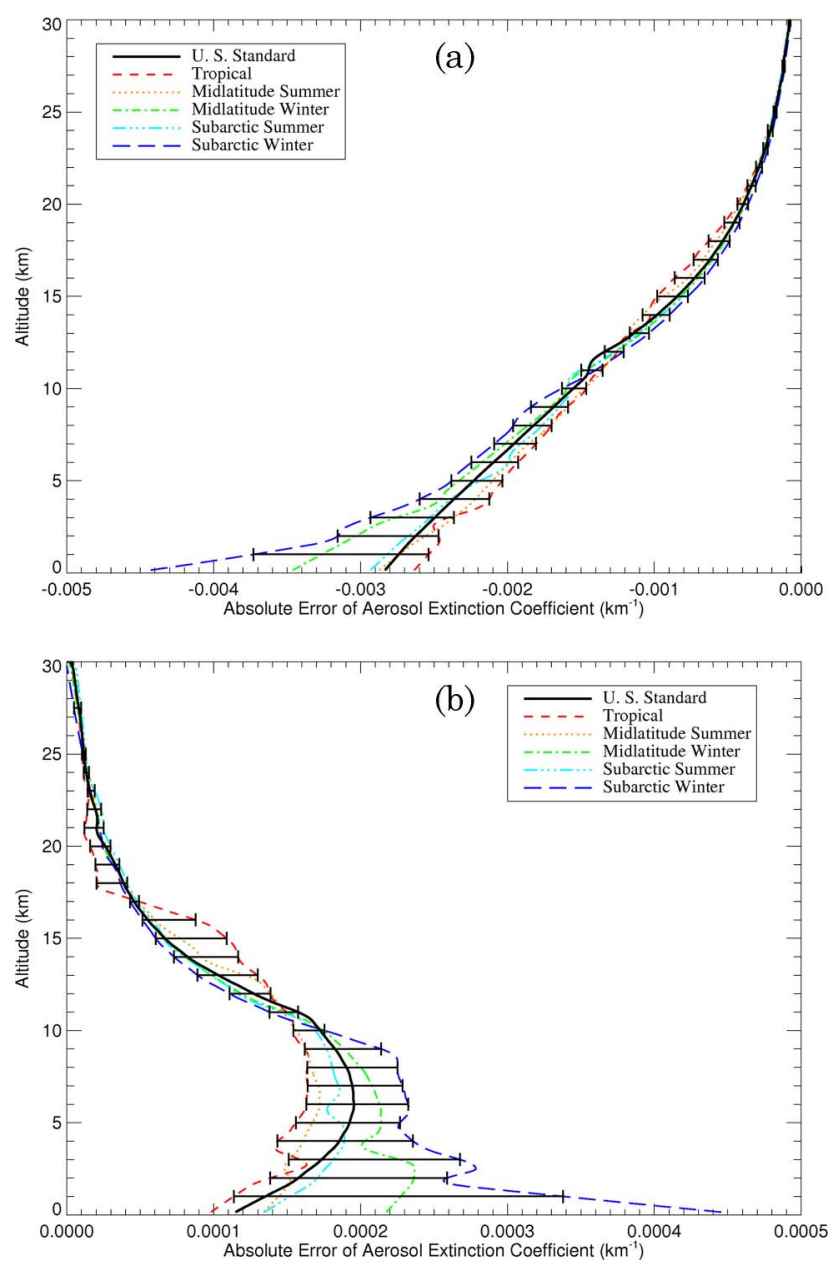

Fig. 5. (Color online) Absolute error of the aerosol extinction coefficient after Eq. (6) from applying (a) the Gaussian model and (b) the S7 model calculated based on the six reference atmospheres. The error bars show the maximum error range due to different models.

normalization height, for both airborne and spaceborne HSRLs, the situations are the same.

Figure 6 shows an example of HSRL-measured aerosol backscatter coefficient profiles on 25 January 2008 retrieved from the $\mathrm{S} 6$ model, the $\mathrm{S} 7$ model, and the Gaussian model. The temperature and pressure profiles are obtained from the nearby radiosonde. Like the example of aerosol extinction coefficient in Fig. 3, the $\mathrm{S} 6$ and $\mathrm{S} 7$ models result in identical profiles, while the Gaussian model yields a profile with smaller values. However, the deviation of the Gaussian profile increases with aerosol concentration but decreases with altitude.

As shown in Eq. (8), the relative error of the aerosol backscatter coefficient $\delta \beta_{a}$ depends not only on altitude and normalization height, but also on the aerosol concentration, which can be described by the backscatter ratio $R_{b}$. The situation for an airborne HSRL with a fixed normalization height is shown in Fig. 7. The experimental results, retrieved from seven HSRL measurements by applying the corresponding individual radiosonde profiles of tempera-

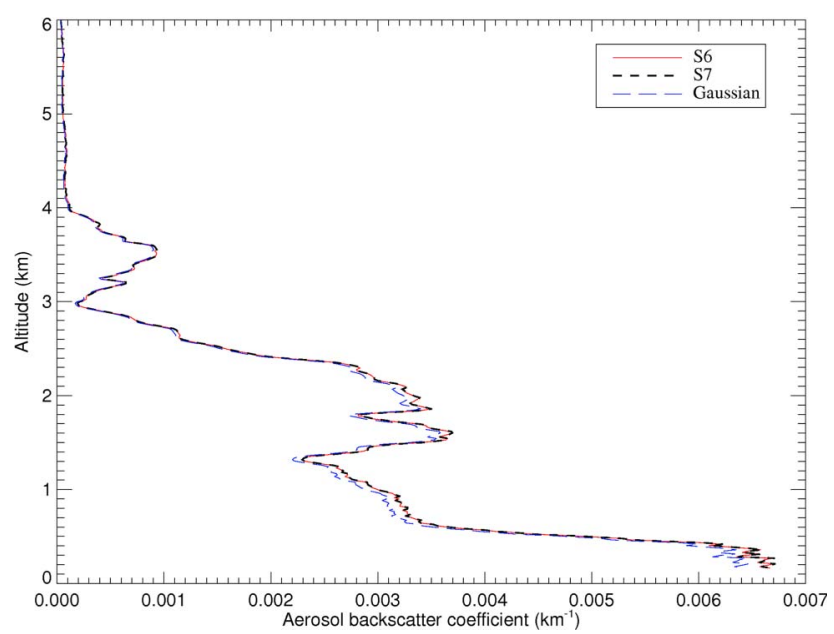

Fig. 6. (Color online) HSRL-measured profiles of the aerosol backscatter coefficient (15:56, 25 January 2008, Praia) retrieved using the S6 model, the S7 model, and the Gaussian model.

ture and pressure, have the same normalization height of $7 \mathrm{~km}$. The experimental data are classified according to the measured backscatter ratio $R_{b}$. The solid lines, which are theoretically calculated using Eq. (8) and the averaged radiosonde data during the HSRL measurements, agree well with the experimental results (different symbols) based on the airborne HSRL measurements. Obviously, the relative errors, which vary significantly in Fig. 7(a), are in inverse proportion to the aerosol concentration as shown in Figs. 7(b)-7(f) . In addition, with given aerosol concentrations, the errors decreasing with altitude are actually determined by the atmospheric temperature and pressure. As shown in Fig. 7(f), at ground level with high aerosol concentration, the minimum value of the errors is approximately $3 \%$. However, when the aerosol backscatter ratio is less than 1.2, the relative error near ground is more than $\sim 20 \%$, as shown in Fig. 7(c).

The results shown in Fig. 7 suggest that the theoretical calculations are correct in case of various flights, aerosol concentrations, and altitudes. Therefore, it can be used for both airborne and spaceborne HSRL analysis. Based on the temperature and pressure profiles of the reference atmospheres, with given backscatter ratios, the relative errors of the aerosol backscatter coefficient induced by the Gaussian model are theoretically calculated using Eq. (ㅇ), as shown in Fig. 8. The normalization heights are $7 \mathrm{~km}$ in Fig. 8(a) and $30 \mathrm{~km}$ in Fig. 8(b), which stand for the cases of airborne and spaceborne HSRL, respectively. It can be seen from Fig. 7, when the normalization height is $30 \mathrm{~km}$, the errors at ground level and $5 \mathrm{~km}$ are approximately 2 and 4 times larger, respectively, than those with a normalization height of $7 \mathrm{~km}$. The results show that the relative errors of aerosol backscatter coefficient caused by the Gaussian model are greatly influenced by the normalization height. With a higher normalization height, the errors become larger. The theoretical comparison of the aerosol backscatter coefficient retrieved from 
Backscatter Ratio > 1.0

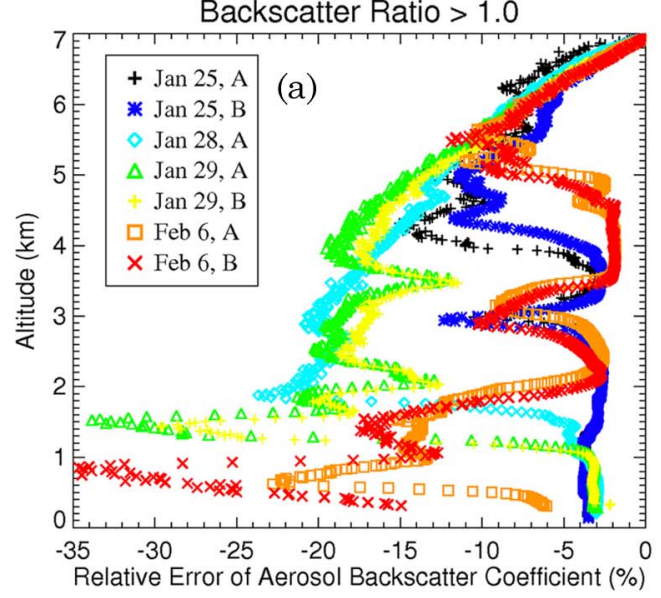

$1.1<$ Backscatter Ratio < 1.2

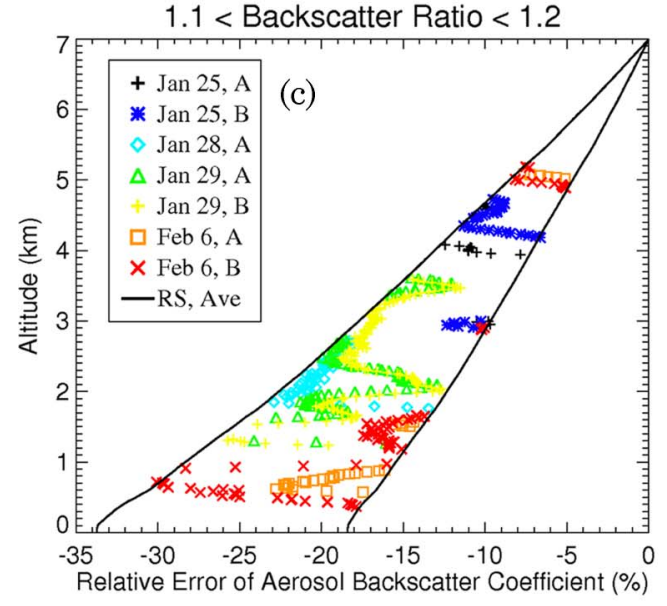

$1.5<$ Backscatter Ratio < 2.0

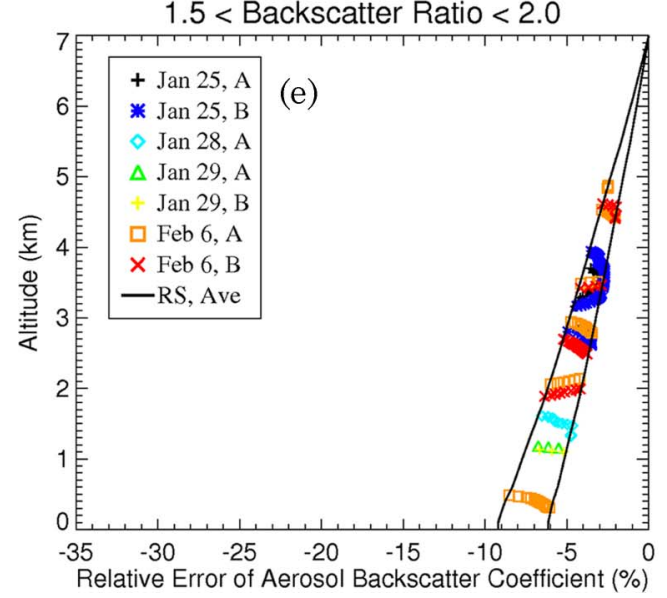

$1.0<$ Backscatter Ratio < 1.1

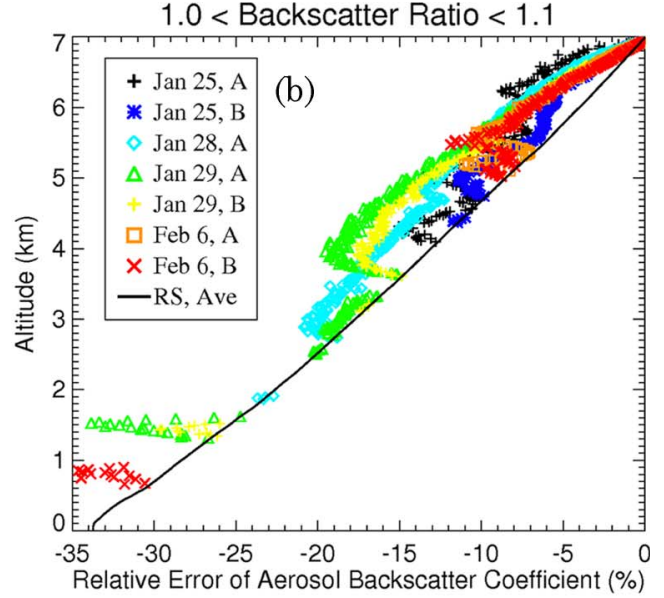

$1.2<$ Backscatter Ratio < 1.5

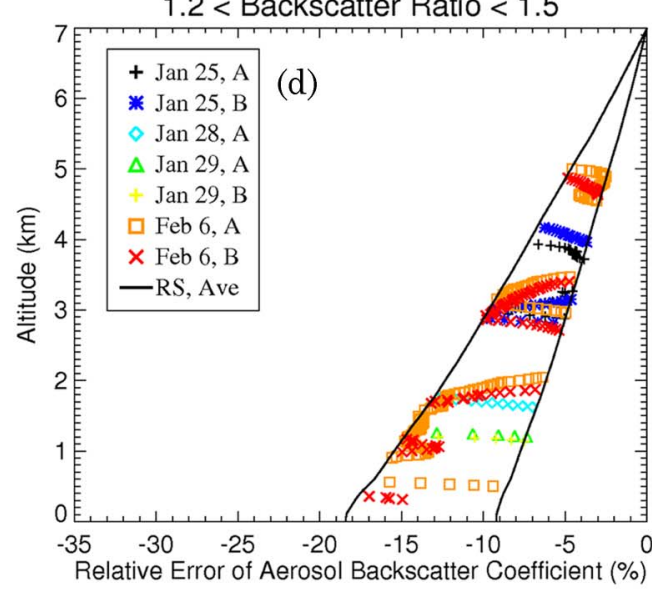

Backscatter Ratio > 2.0

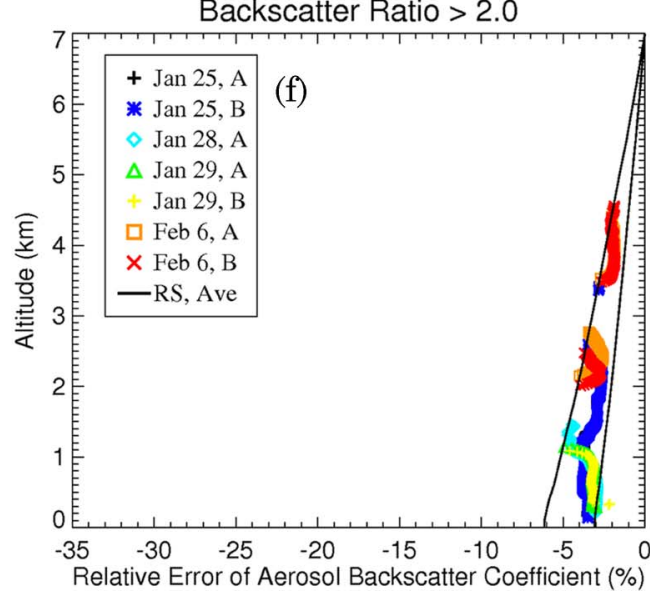

Fig. 7. (Color online) Relative errors of the aerosol backscatter coefficient after Eq. (8) from applying the Gaussian model retrieved from seven HSRL measurements classified by the backscatter ratio. The normalization height is $7 \mathrm{~km}$ for the HSRL retrieval. The solid curves are errors theoretically calculated using Eq. () from averaged radiosonde data during the HSRL measurements.

the S7 model and the S6 model is shown in Fig. 9. The normalization heights are $7 \mathrm{~km}$ in Fig. $9(\bar{a})$ and $30 \mathrm{~km}$ in Fig. 9(b), respectively. The tren of the errors is similar to that in Fig. 8, but the values are approximately 1 order of magnitude smaller. For both airborne and spaceborne systems, when the aerosol concentration is low, the errors are observable at low altitude.

\section{Example of Aerosol Optical Thickness Retrieved from Different Models}

To provide an example of the influence of backscatter models on the aerosol optical properties, a comparison of the aerosol optical thickness measured with airborne HSRL and the sunphotometer is presented. The values of aerosol optical thickness are retrieved from HSRL measurements with different models, 

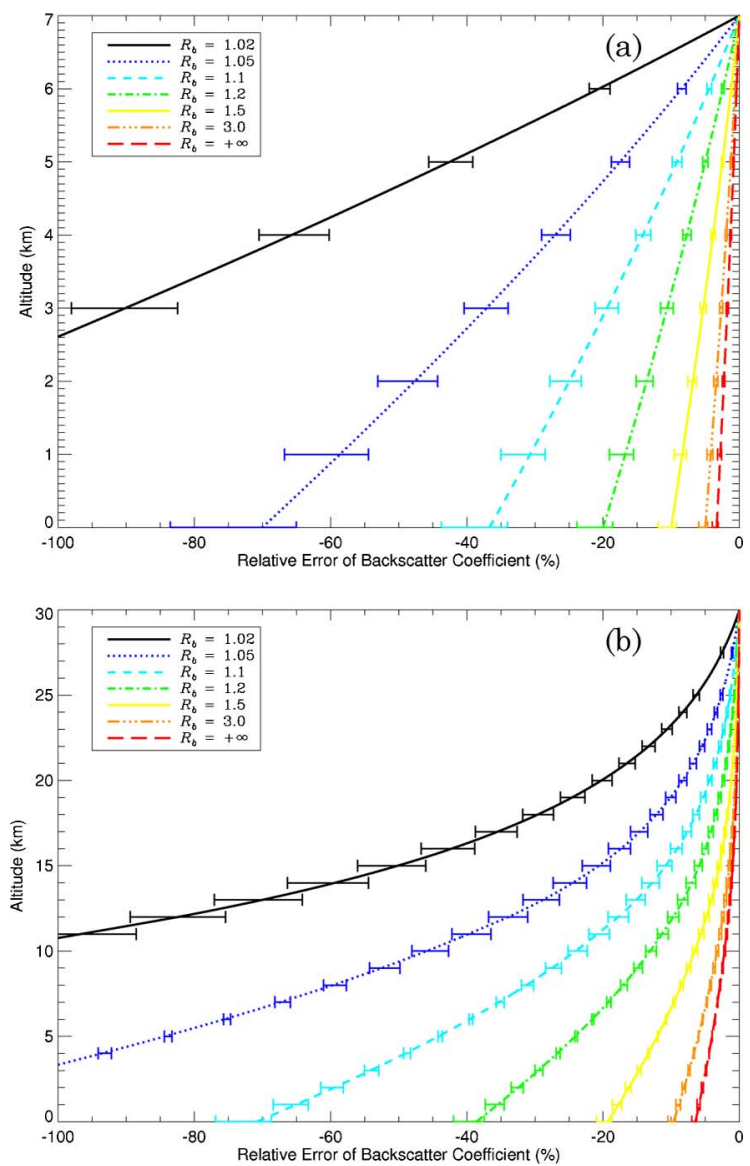

Fig. 8. (Color online) Relative errors of the aerosol backscatter coefficient after Eq. (8) caused by the Gaussian model calculated based on the U.S. standard atmosphere (curves) with given backscatter ratios $\left(R_{b}\right)$. The error bars show the error range due to the six different reference atmospheres. The normalization height is (a) $7 \mathrm{~km}$ and (b) $30 \mathrm{~km}$ for the calculation.
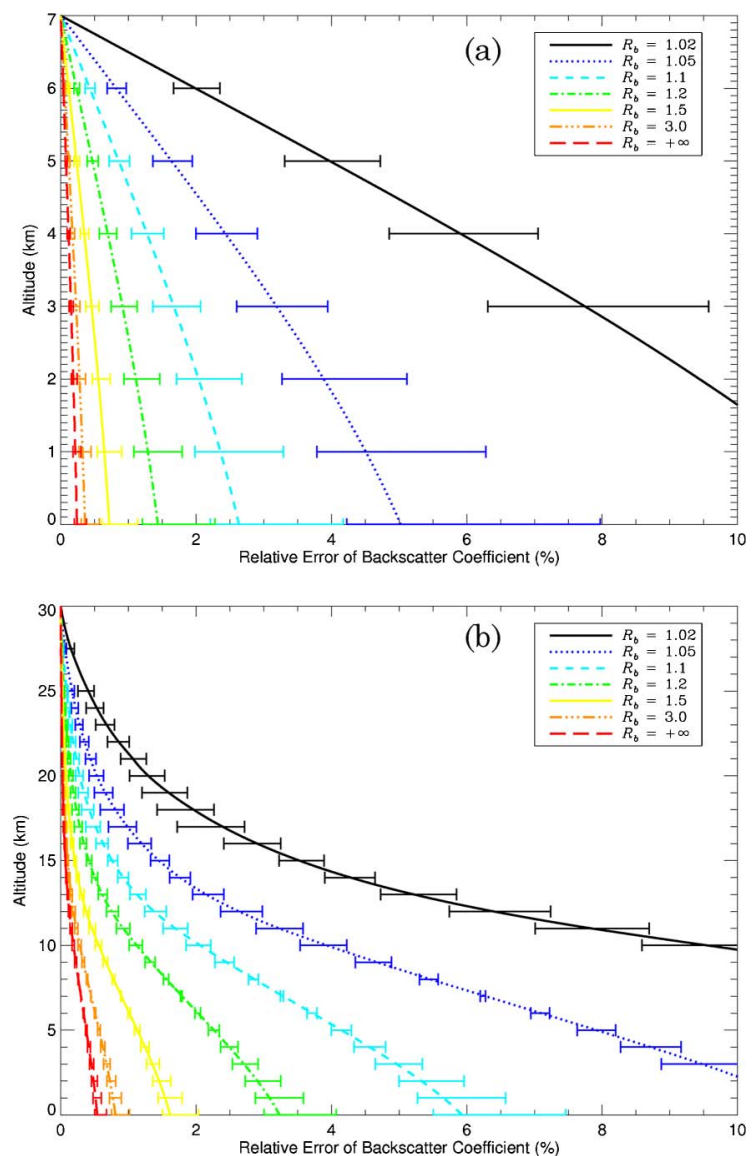

Fig. 9. (Color online) Relative errors of the aerosol backscatter coefficient after Eq. (8) caused by the S7 model calculated based on the U. S. standard atmosphere (curves) with given backscatter ratios $\left(R_{b}\right)$. The error bars show the error range due to the six different reference atmospheres. The normalization height is (a) $7 \mathrm{~km}$ and (b) $30 \mathrm{~km}$ for the calculation.

Table 2. Flight Legs Used for the Comparison of the Aerosol Optical Thickness Measured with Airborne HSRL and Sunphotometer

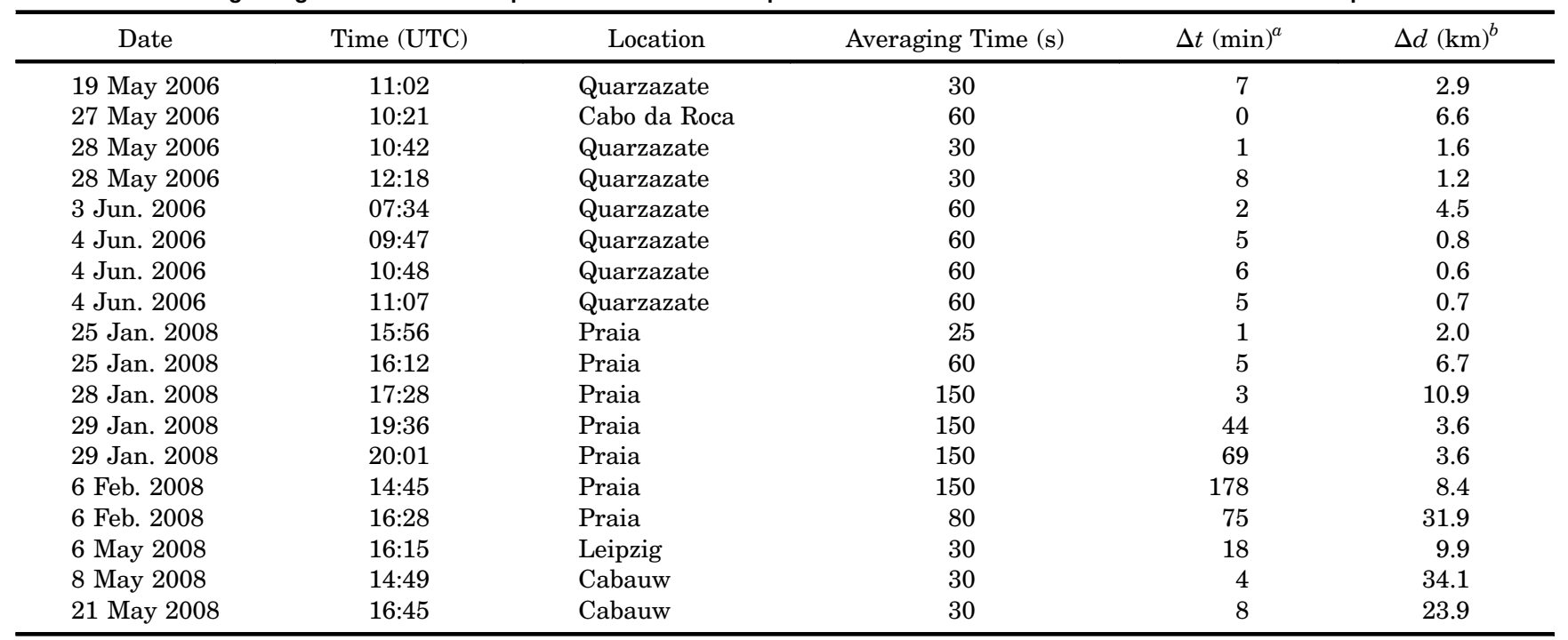

${ }^{a}$ Time interval between HSRL and sunphotometer measurements.

${ }^{b}$ Distance between HSRL and sunphotometer measurements. 
and compared to the Aerosol Robotic Network (AERONET) sunphotometer measurements. The experimental data of the DLR airborne HSRL during the SAMUM 2006, SAMUM 2008, and the European Integrated Project on Aerosol Cloud Climate Air Quality Interactions (EUCAARI) 2008 field campaigns are used in this analysis. The flight legs of the HSRL measurement used for comparison are shown in Table 2. The aerosol optical thickness of the HSRL is obtained from the measured profile by averaging the last five range bins above ground. The standard deviation of the five range bins is considered as the measurement error. For comparison purposes, the sunphotometer aerosol optical thickness at $532 \mathrm{~nm}$ is determined from the measurements at 440,675 , and, if available, $500 \mathrm{~nm}$ by interpolation.

Figure 10 shows the scatter plot of the aerosol optical thickness measured with airborne HSRL and sunphotometers. To show the influence of the model, the HSRL results are retrieved using the Gaussian model and the Tenti S6 model. The difference of the models leads to almost constant deviations of aerosol optical thickness, as shown in Fig. 10, which agrees with the theoretical analysis shown in Eq. (A4). The average value of the deviations is comparable to the measurement errors of the airborne HSRL, which are indicated by error bars in Fig. 10 . Furthermore, there are several origins for the deviations between airborne HSRL and sunphotometer measurements, such as viewing angle, and temporal and spatial difference. Therefore, the advantage of the S6 model over the Gaussian model cannot be validated only from the scatter plot of the aerosol optical thickness based on the limited data base. For both

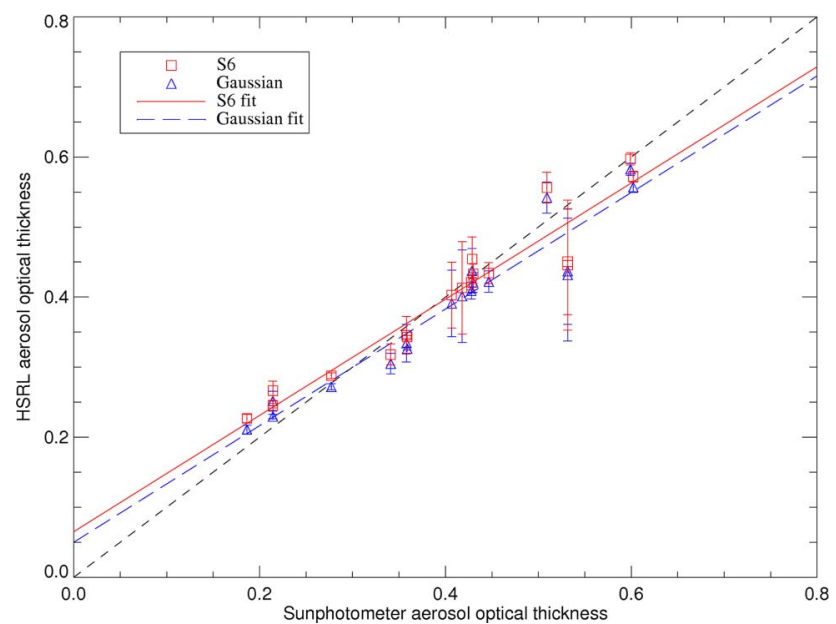

Fig. 10. (Color online) Comparison of the aerosol optical thickness measured by airborne HSRL and the sunphotometer at 18 aircraft overpasses during the SAMUM 2006, the SAMUM 2008, and the EUCAARI 2008 field campaigns. The HSRL measurements are retrieved using the $\mathrm{S} 6$ model and the Gaussian model. The error bars indicate the measurement error of the airborne HSRL. The solid curve and the dashed curve show the linear least-squares fit for the results from the $\mathrm{S} 6$ model and the Gaussian model, respectively. the Gaussian and the S6 models, a linear leastsquares fit of 18 data points results in a similar slope. However, in the case of using the $\mathrm{S} 6$ model, the average bias between HSRL and sunphotometer data, which is -0.0035 , is much smaller than the value of -0.0185 in the case of the Gaussian model.

\section{Conclusion}

The spectral distribution of the Cabannes scattering from air molecules can theoretically be described by different models, which may induce errors in the aerosol optical properties retrieved by HSRL. In this paper, the influence of three theoretical models of molecular scattering on the retrieval of aerosol optical properties observed by airborne HSRL was experimentally investigated and theoretically calculated. The aerosol optical properties are retrieved from HSRL measurements with the $\mathrm{S} 6$ model, the S7 model, and the Gaussian model, and the deviations induced by the models are analyzed and quantified. The errors are calculated using the six mostused reference atmospheres, which include the typical profiles of temperature and pressure from tropic to subarctic, so the influence of the scattering models for the spaceborne HSRL can be evaluated over a global range. The results suggest the following. (a) The S6 and S7 models yield identical aerosol optical properties with almost unobservable deviations, which, theoretically, are approximately 1 order of magnitude less than that of the deviations caused by the Gaussian model. (b) The absolute errors of the aerosol extinction coefficient induced by the Gaussian model are less than the molecular extinction coefficient at the same altitude and can generally be neglected. (c) The relative errors of the aerosol backscatter coefficient from applying the Gaussian model are in proportion to the normalization height but decrease with both altitude and aerosol concentration. For an airborne HSRL with a normalization height of $7 \mathrm{~km}$, the errors at ground level are 3\%-20\% when the backscatter ratio is larger than 1.2. The errors at ground level for a spaceborne HSRL with a normalization height of $30 \mathrm{~km}$ are approximately 2 times larger than those of the airborne HSRL, which are considerable, especially when the aerosol concentration is low. (d) The comparison of the HSRL aerosol optical thickness with sunphotometer measurements shows that the influence of the Gaussian model is observable and the average bias of the Gaussian results is larger than that of the $\mathrm{S} 6$ results. However, the statistics are limited by the amount of the data. In brief, this study shows that, in the case of an airborne HSRL, the errors are not too high, but that, in the case of a spaceborne HSRL, the errors of the aerosol backscatter coefficient are quite high.

It should be noted that the Tenti S6 model was developed and experimentally validated for pure gases with single species, so the effort to investigate the spectral distribution of molecular scattering in the case of air composition is needed for both the model study and the lidar applications. 


\section{Appendix A: Retrieval Errors of the Aerosol Optical Properties due to the Models}

By using different theoretical backscatter models, the calculation of the attenuation factor $f_{m}$ results in a different value. The deviations of the $f_{m}$ derived from the Gaussian or S7 model and the S6 model are considered as errors to investigate the influence of the Gaussian and the S7 models on the aerosol optical properties. The relative error of the normalized attenuation factor is defined as

$$
\begin{aligned}
& \delta f_{m, i, j}^{\prime}(r)=\frac{f_{m, i}(r) / f_{m, i}\left(r_{0}\right)-f_{m, j}(r) / f_{m, j}\left(r_{0}\right)}{f_{m, j}(r) / f_{m, j}\left(r_{0}\right)}, \\
& i, j=\mathrm{S} 6, \mathrm{~S} 7, \mathrm{G},
\end{aligned}
$$

where $r_{0}$ is the normalization height where the Rayleigh normalization is performed. At the normalization height $r_{0}$, with the measured or assumed backscatter ratio $R_{b}\left(r_{0}\right)$, the received signal $E_{t}\left(r_{0}\right)$ in the total scattering channel and $E_{m}\left(r_{0}\right)$ in the molecular channel, and the calculated molecular transmission factor $f_{m}\left(r_{0}\right)$, the channel efficiency $\eta_{m}$ in the molecular channel can be expressed as

$$
\eta_{m, i}=\eta_{t} \frac{E_{m}\left(r_{0}\right)}{E_{t}\left(r_{0}\right)} \frac{R_{b}\left(r_{0}\right)}{f_{m, i}\left(r_{0}\right)}, \quad i, j=\mathrm{S} 6, \mathrm{~S} 7, \mathrm{G}
$$

where S6, S7, and G stand for the S6 model, the S7 model, and the Gaussian model, respectively. It should be noted that molecular transmission factor $f_{m}\left(r_{0}\right)$ is determined by the molecular scattering model, so the channel efficiency $\eta_{m}$ in the molecular is dependent on the scattering model and the normalization height $r_{0}$. That is why the errors of the aerosol optical thickness, the backscatter ratio, and the aerosol backscatter coefficient depend on the normalization height $r_{0}$.

From the measurement in the molecular channel as shown in Eq. (2b), the aerosol optical thickness $t_{a}(r)$ can be derived as

$$
t_{a}(r)=-\frac{1}{2}\left[\ln \frac{E_{m}(r) r^{2}}{\eta_{m} E_{0} A \Delta r \beta_{m}(r) f_{m}(r) \tau_{m}^{2}(r)}\right],
$$

where the constant $\eta_{m} E_{0} A \Delta r$ can be obtained by substituting $E_{m}\left(r_{0}\right), f_{m}\left(r_{0}\right)$, and $\tau^{2}\left(r_{0}\right)=1$ into Eq. (2b). Then the absolute error $\Delta t_{a}(r)$ follows from Eq. $(\underline{\overline{\mathrm{A} 3}})$ :

$$
\begin{aligned}
\Delta t_{a, i, j}(r) & =-\frac{1}{2}\left[\ln \frac{f_{m, i}\left(r_{0}\right)}{f_{m, i}(r)}-\ln \frac{f_{m_{, j}}\left(r_{0}\right)}{f_{m, j}(r)}\right] \\
& =\frac{1}{2} \ln \left[f_{m, i, j}^{\prime}(r)+1\right] .
\end{aligned}
$$

For the calculation of the absolute error of aerosol extinction coefficient $\Delta a_{a}$, since in Eq. (3) only the term $f_{m}(r)$ depends on the theoretical backscatter model, $\Delta a_{a}$ defined in Eq. (5a) can be derived as follows:

$$
\begin{aligned}
\Delta \alpha_{a, i, j}(r) & =\frac{1}{2} \frac{d}{d r}\left[\ln \frac{f_{m, i}(r)}{f_{m, j}(r)}\right] \\
& =\frac{1}{2}\left[\frac{d f_{m, i}(r) / d r}{f_{m, i}(r)}-\frac{d f_{m, j}(r) / d r}{f_{m, j}(r)}\right] .
\end{aligned}
$$

The relative error of the backscatter ratio, $\delta R_{b}$, defined in Eq. (5b) can be obtained with Eqs. (4a) and (A2) as

$$
\delta R_{b, i, j}(r)=\frac{\eta_{m, i} f_{m, i}(r)-\eta_{m, j} f_{m, j}(r)}{\eta_{m, j} f_{m, j}(r)}=\delta f_{m, i, j}^{\prime}(r) .
$$

The relative error of the aerosol backscatter coefficient $\delta \beta_{a}$ is derived with Eqs. (나) and (A2) as

$$
\begin{aligned}
\delta \beta_{a, i, j}(r) & =\frac{E_{t}(r)}{E_{m}(r)} \frac{\eta_{m, i} f_{m, i}(r)-\eta_{m, j} f_{m, j}(r)}{\eta_{t} \beta_{a, j}(r) / \beta_{m}(r)} \\
& =\left[\frac{\beta_{m}(r)}{\beta_{a, j}(r)}+1\right] \delta f_{m, i, j}^{\prime}(r) .
\end{aligned}
$$

The authors thank Albert Ansmann of Leibniz Institute for Tropospheric Research, Frank Wagner of Universidade de Evora, Brent Holben of NASA, and Gerrit de Leeuw of Finnish Meteorological Institute for providing the sunphotometer data and Mikhail N. Shneider of Princeton University for providing the FORTRAN program of the S7 model. We thank two anonymous reviewers who provided helpful suggestions and comments.

\section{References}

1. A. Romanou, B. Liepert, G. A. Schmidt, W. B. Rossow, R. A. Ruedy, and Y. Zhang, "20th century changes in surface solar irradiance in simulations and observations," Geophys. Res. Lett. 34, L05713 (2007).

2. J. D. Spinhirne, S. P. Palm, W. D. Hart, D. L. Hlavka, and E. J. Welton, "Cloud and aerosol measurements from GLAS: Overview and initial results," Geophys. Res. Lett. 32, L22S03 (2005).

3. B. E. Schutz, H. J. Zwally, C. A. Shuman, D. Hancock, and J. P. DiMarzio, "Overview of the ICESat Mission," Geophys. Res. Lett. 32, L21S01 (2005).

4. D. M. Winker, W. H. Hunt, and C. A. Hostetler, "Status and performance of the CALIOP lidar," Proc. SPIE 5575, 8-15 (2004).

5. D. M. Winker, J. R. Pelon, and M. P. McCormick, "The CALIPSO mission: spaceborne lidar for observation of aerosols and clouds," Proc. SPIE 4893, 1-11 (2003).

6. J. D. Klett, "Stable analytical inversion solution for processing lidar returns," Appl. Opt. 20, 211-220 (1981).

7. F. G. Fernald, "Analysis of atmospheric lidar observations: some comments," Appl. Opt. 23, 652-653 (1984).

8. S. T. Shipley, D. H. Tracy, E. W. Eloranta, J. T. Trauger, J. T. Sroga, F. L. Roesler, and J. A. Weinman, "High spectral resolution lidar to measure optical scattering properties of atmospheric aerosols. 1: Theory and instrumentation,” Appl. Opt. 22, 3716-3724 (1983).

9. H. Shimizu, S. A. Lee, and C. Y. She, "High spectral resolution lidar system with atomic blocking filters for measuring atmospheric parameters," Appl. Opt. 22, 1373-1381 (1983). 
10. R. J. Alvarez II, L. M. Caldwell, Y. H. Li, D. A. Krueger, and C. Y. She, "High-spectral-resolution lidar measurement of tropospheric backscatter-ratio with barium atomic blocking filters," J. Atmos. Ocean. Technol. 7, 876-881 (1990).

11. P. Piironen and E. W. Eloranta, "Demonstration of a highspectral-resolution lidar based on an iodine absorption filter," Opt. Lett. 19, 234-236 (1994).

12. Z. Liu, I. Matsui, and N. Sugimoto, "High-spectral-resolution lidar using an iodine absorption filter for atmospheric measurements," Opt. Eng. 38, 1661-1670 (1999).

13. J. W. Hair, L. M. Caldwell, D. A. Krueger, and C. Y. She, "Highspectral-resolution lidar with iodine-vapor filters: measurement of atmospheric-state and aerosol profiles," Appl. Opt. 40, 5280-5294 (2001).

14. J. W. Hair, C. A. Hostetler, R. A. Ferrare, A. L. Cook, and D. B. Harper, "The NASA Langley airborne high spectral resolution lidar for measurements of aerosols and clouds," in Reviewed and Revised Papers Presented at the 23rd International Laser Radar Conference, C. Nagasawa and N. Sugimoto, eds. (2006), pp. 411-414.

15. J. W. Hair, C. A. Hostetler, A. L. Cook, D. B. Harper, R. A. Ferrare, T. L. Mack, W. Welch, L. R. Izquierdo, and F. E. Hovis, "Airborne high spectral resolution lidar for profiling aerosol optical properties," Appl. Opt. 47, 6734-6752 (2008).

16. U. Wandinger, D. Müller, C. Böckmann, D. Althausen, V. Matthias, J. Bösenberg, V. Weiss, M. Fiebig, M. Wendisch, A. Stohl, and A. Ansmann, "Optical and microphysical characterization of biomass-burning and industrial-pollution aerosols from multiwavelength lidar and aircraft measurements," J. Geophys. Res. 107, 8125 (2002).

17. M. Esselborn, M. Wirth, A. Fix, M. Tesche, and G. Ehret, "Airborne high spectral resolution lidar for measuring aerosol extinction and backscatter coefficients," Appl. Opt. 47, 346-358 (2008).

18. M. Esselborn, M. Wirth, A. Fix, B. Weinzierl, K. Rasp, M. Tesche, and A. Petzold, "Spatial distribution and optical properties of Saharan dust observed by airborne high spectral resolution lidar during SAMUM 2006," Tellus B 61, 131-143 (2009).

19. M. Wirth, A. Fix, P. Mahnke, H. Schwarzer, F. Schrandt, and G. Ehret, "The airborne multi-wavelength water vapor differential absorption lidar WALES: system design and performance," Appl. Phys. B. 96, 201-213 (2009).

20. M. Endemann, P. Dubock, P. Ingmann, R. Wimmer, D. Morançais, and D. Demuth, "The ADM-AEOLUS missionthe first wind lidar in space," in Proceedings of 22nd International Laser Radar Conference, ESA SP-561(2) (European Space Agency, 2004), pp. 953-956.

21. European Space Agency, "ADM-Aeolus, science report," ESA SP-1311 (European Space Research and Technology Centre, 2008).

22. European Space Agency, "Atmospheric dynamics mission, report for mission selection," ESA SP-1233(4) (European Space Research and Technology Centre, 1999).

23. A. Stoffelen, J. Pailleux, E. Källén, J. M. Vaughan, L. Isaksen, P. Flamant, W. Wergen, E. Andersson, H. Schyberg, A. Culoma, R. Meynart, M. Endemann, and P. Ingmann, "The atmospheric dynamics mission for global wind field measurements," Bull. Am. Meteorol. Soc. 86, 73-87 (2005).

24. A. Ansmann, U. Wandinger, O. Le Rille, D. Lajas, and A. G. Straume, "Particle backscatter and extinction profiling with the spaceborne high-spectral-resolution Doppler lidar ALADIN: methodology and simulations," Appl. Opt. 46, 6606-6622 (2007).

25. P. Flamant, J. Cuesta, M.-L. Denneulin, A. Dabas, and D. Huber, "ADM-Aeolus retrieval algorithms for aerosol and cloud products," Tellus A 60, 273-288 (2008).

26. European Space Agency, "Earth Clouds, Aerosols, and Radiation Explorer," ESA SP-1279(1) (European Space Research and Technology Centre, 2004).

27. Y. Durand, A. Hélière, J.-L. Bézy, and R. Meynart, "The ESA EarthCARE mission: results of the ATLID instrument predevelopments," Proc. SPIE 6750, 675015 (2007).

28. A. Young, "Rayleigh scattering," Appl. Opt. 20, 533-535 (1981).

29. A. Young, "Rayleigh scattering," Phys. Today 35, 42-48 (1982).

30. C. Y. She, "Spectral structure of laser light scattering revisited: bandwidths of nonresonant scattering lidars," Appl. Opt. 40, 4875-4884 (2001).

31. G. Tenti, C. Boley, and R. Desai, "On the kinetic model description of Rayleigh-Brillouin scattering from molecular gases," Can. J. Phys. 52, 285-290 (1974).

32. X. Pan, M. Shneider, and R. Miles, "Coherent RayleighBrillouin scattering in molecular gases," Phys. Rev. A 69, 033814 (2004).

33. Q. Zheng, "Model for polarized and depolarized RayleighBrillouin scattering spectra in molecular gases," Opt. Express 15, 14257-14265 (2007).

34. A. Young and G. Kattawar, "Rayleigh-scattering line profiles," Appl. Opt. 22, 3668-3670 (1983).

35. L. Landau and G. Placzek, "Structure of the undisplaced scattering line,” Phys. Z. Sowiet. Un. 5, 172 (1934).

36. J. N. Forkey, "Development and demonstration of filtered Rayleigh scattering - a laser based flow diagnostic for planar measurement of velocity, temperature and pressure," Ph.D. dissertation (Princeton University, 1996).

37. M. Shneider, Department of Mechanical and Aerospace Engineering, Princeton University, New Jersey 08544, USA (personal communication, 2009).

38. G. P. Anderson, S. A. Clough, F. X. Kneizys, J. H. Chetwynd, and E. P. Shettle, "AFGL atmospheric constituent profiles (0-120 km)," AFGL-TR-86-0110 (Air Force Geophysics Laboratory, 1986).

39. T. Pain, P. Martimort, P. Tanguy, W. Leibrandt, and A. Hélière, "ATLID: atmospheric lidar four clouds and aerolsol observations combined with radar sounding," in Proceedings of the 5th International Conference on Space Optics, B. Warmbein ed., ESA SP-554 (European Space Agency, 2004), pp. 19-23.

40. European Space Agency, "WALES-Water Vapour Lidar Experiment in Space," ESA SP-1279(3) (European Space Research and Technology Centre, 2004).

41. S. Gerstenkorn and P. Luc, Atlas du Spectre D'Absorption de la Molecule D'Iode (CNRS, 1978).

42. R. Miles, W. Lempert, and J. Forkey, "Laser Rayleigh scattering," Meas. Sci. Technol. 12, R33-R51 (2001).

43. A. Savitzky and M. Golay, "Smoothing and differentiation of data by simplified least square procedures," Anal. Chem. 36, 1627-1639 (1964).

44. S. Palm, W. Hart, D. Hlavka, E. Welton, A. Mahesh, and J. Spinhirne, "GLAS atmospheric data products, algorit $\mathrm{hm}$ theoretical basis document, version 4.2," (Goddard Space Flight Center, 2002, last accessed 2 June 2009) http://www. csr.utexas.edu/glas/pdf/glasatmos.atbdv4.2.pdf. 